\title{
QUEEN'S
UNIVERSITY
BELFAST
}

\section{Changes in pain during buprenorphine maintenance treatment among patients with opioid use disorder and chronic pain}

\author{
Edwards, K. A., Vowles, K. E., McHugh, R. K., Venner, K. L., \& Witkiewitz, K. (2022). Changes in pain during \\ buprenorphine maintenance treatment among patients with opioid use disorder and chronic pain. Journal of \\ Consulting and Clinical Psychology. https://doi.org/10.1037/ccp0000692
}

Published in:

Journal of Consulting and Clinical Psychology

\section{Document Version:}

Peer reviewed version

Queen's University Belfast - Research Portal:

Link to publication record in Queen's University Belfast Research Portal

\section{Publisher rights}

Copyright 2021, American Psychological Association

This work is made available online in accordance with the publisher's policies. Please refer to any applicable terms of use of the publisher

\section{General rights}

Copyright for the publications made accessible via the Queen's University Belfast Research Portal is retained by the author(s) and / or other copyright owners and it is a condition of accessing these publications that users recognise and abide by the legal requirements associated with these rights.

Take down policy

The Research Portal is Queen's institutional repository that provides access to Queen's research output. Every effort has been made to ensure that content in the Research Portal does not infringe any person's rights, or applicable UK laws. If you discover content in the Research Portal that you believe breaches copyright or violates any law, please contact openaccess@qub.ac.uk. 


\section{Changes in Pain During Buprenorphine Maintenance Treatment among Patients with Opioid Use Disorder and Chronic Pain}

Karlyn A. Edwards, $\mathrm{PhD}^{1}$, Kevin E. Vowles, $\mathrm{PhD}^{2}$, R. Kathryn McHugh, $\mathrm{PhD}^{3}$, Kamilla L. Venner, $\mathrm{PhD}^{4}$, and Katie Witkiewitz, $\mathrm{PhD}^{4}$

${ }^{1}$ Department of Anesthesiology, Preoperative, and Pain Medicine, Division of Pain Medicine, Stanford University

${ }^{2}$ School of Psychology, Queen's University Belfast

${ }^{3}$ McLean Hospital \& Harvard Medical School, Harvard University

${ }^{4}$ Department of Psychology \& Center on Alcohol, Substance use, and Addiction (CASAA), University of New Mexico

\section{Author Note}

Dr. Venner provides training and consultation in evidence-based treatments for a fee and has a management plan in place with University of New Mexico. There are no other conflicts of interest to disclose.

Correspondence regarding this article should be addressed to Karlyn A. Edwards, 1070 Arastradero Road, Suite 200, MC 5596, Palo Alto, CA 94304. Email: karlyne@ stanford.edu. 


\begin{abstract}
Objective: Opioid use disorder (OUD) and chronic pain frequently co-occur. Little is known about changes in pain during buprenorphine/naloxone (BUP/NX) maintenance and whether outcomes vary by pain levels. The current study examined changes in pain intensity and pain interference over 12 weeks of BUP/NX maintenance among participants with OUD and chronic pain $(\mathrm{N}=194)$. Differences in outcomes were assessed during BUP/NX maintenance (week 12) and two months following a BUP/NX taper (week 24). Method: Data from Phase 2 of the Prescription Opioid Addiction Treatment Study were used. Two latent transition models were conducted to characterize profiles and transitions between profiles of pain intensity or pain interference (estimated separately). Results: Each model identified a high and low profile. In the pain interference model, the majority were classified in the low profile at baseline. In the pain intensity model, the majority were classified in the high profile at baseline. In both models, patients were more likely to remain in or transition to the low profiles by week 12 . Worse depression was associated with membership in the high pain interference profile at both timepoints. Women were more likely to be in the high pain intensity profile at baseline. Those in the high pain intensity and high pain interference profiles at week 12 reported worse mental health quality of life at week 12 , as well as high pain intensity and high pain interference at week 24. Conclusions: For a subgroup of patients, high pain intensity and high pain interference remains unchanged during BUP/NX maintenance treatment.
\end{abstract}

Keywords: Chronic pain, opioid use disorder, buprenorphine, latent transition modeling. 
Public Health Statement: Among those with opioid use disorder and chronic pain, a subgroup of patients continue to have high pain intensity and pain interference during buprenorphine maintenance treatment. Worse depression severity is related to high pain interference. High pain intensity and pain interference are related to worse mental health quality of life. 


\section{Changes in Pain During Buprenorphine Maintenance Treatment among Patients with Opioid Use Disorder and Chronic Pain}

Approximately $4.4 \%$ of the United States population uses opioids not as prescribed (i.e. misuse) and about $1 \%$ meet criteria for opioid use disorder (OUD; Centers for Disease Control and Prevention, 2018). Rates of opioid misuse and OUD among those with chronic pain are significantly higher: approximately $21-29 \%$ of patients and $8-12 \%$, respectively (Vowles et al., 2015). Additionally, chronic pain is among the most frequently co-occurring diagnoses among those with OUD, ranging from 49 to $64 \%$ (Hser et al., 2017; Wollschlaeger et al., 2017). The current gold standard treatment is medication treatment for OUD (MOUD), of which the most frequently prescribed are methadone and buprenorphine (Volkow et al., 2018).

While previous work has suggested that MOUD alone may be effective for the treatment of chronic pain in people with OUD (Daitch et al., 2014), patients taking MOUD with chronic pain consistently exhibit worse health-related quality of life and distress, more disruptions in social and physical functioning, and poorer sleep quality in comparison to those without chronic pain (Dunn et al., 2015; Griffin et al., 2016; Ilgen et al., 2006; Jamison et al., 2000). Those with chronic pain also benefit less from MOUD in comparison to those without chronic pain, suggesting there may be additional treatment needs (Ilgen et al., 2006). Finally, MOUD appears to have limited analgesic effects in those with OUD and chronic pain (Lazaridou et al., 2020). Therefore, MOUD alone may be insufficient for the management of co-occurring OUD and chronic pain.

Prior work has examined whether the presence of chronic pain at the time of MOUD induction predicts opioid relapse. While a meta-analysis found no evidence that chronic pain predicts illicit opioid use (Dennis et al., 2015), differences in relapse have emerged when 
proximal measurements of pain were examined. Thus, longitudinal differences may indicate differences not evident in cross-sectional data. For example, the Prescription Opioid Addiction Treatment Study (POATS) clinical trial, which enrolled individuals with OUD seeking MOUD treatment, found no differences in rates of opioid relapse based on chronic pain status at baseline (Weiss et al., 2011). When these same trial data were used to examine weekly pain intensity in those with chronic pain, however, highly volatile pain was a risk for opioid relapse during both the active MOUD treatment phase and after MOUD taper (Worley et al., 2015, 2017). Further, higher current pain severity increased the probability of opioid use the following week (Griffin et al., 2016), which was mediated by opioid craving (Messina \& Worley, 2019).

Overall, these findings suggest that there may be aspects of chronic pain, beyond a simple assessment of its presence or absence, that may influence rates of opioid relapse. For example, many studies indicate that pain's interference on functioning is an important consideration, perhaps more so than pain's intensity. While chronic pain is likely to persist over the longer term (Andersson, 2004), reduction in pain intensity does not appear necessary for decreases in pain's interference on functioning (Vowles et al., 2017). Further, pain interference is significantly related to important chronic pain treatment targets, such as pain acceptance and pain catastrophizing, even after controlling for pain intensity among those with chronic pain and OUD (Mun et al., 2019). Hazardous substance use has also been found to be differentially related to pain interference and pain intensity (Jones et al., 2017; Ngo et al., 2021), suggesting that, although related, pain interference may involve a distinct underlying phenomenon separate from pain intensity. Therefore, it is important to examine pain interference independently. Prior work has often summed scores of pain intensity and pain interference together, which may be diluting important differences between the two mechanisms. Endorsement of severe pain interference is 
prevalent among those with chronic pain in MOUD treatment (Dunn et al., 2014), however more work examining changes in pain interference and its unique relation to treatment outcomes, including relapse, is needed.

There is also a need for a nuanced assessment of treatment outcomes in those with MOUD. Prior work among those with chronic pain in MOUD treatment has almost exclusively focused on relapse as the sole outcome for treatment success. However, there are additional criteria that should be evaluated, including physical, psychological, and social functioning (Tiffany et al., 2012). Quality of life, in particular, is an important patient-centered outcome that assesses disease burden, and is sensitive to changes in opioid use and pain-related functioning (Bray et al., 2017; Dworkin et al., 2008).

Finally, patient characteristics should also be taken into consideration, as they may impact changes in pain interference, pain intensity, and subsequent treatment outcomes. Older age, being female, longer pain duration, and higher psychiatric distress have been related to worse pain severity and pain interference among those with chronic pain (Landmark et al., 2018). In particular, depression is one of the most common comorbidities in chronic pain and OUD populations and has been implicated in the development and maintenance of both conditions (Edwards et al., 2016; Volkow et al., 2019). Emotional functioning is also associated with pain sensitivity and pain tolerance, particularly in the context of opioid use (Wachholtz et al., 2015). Overall, broader inclusion of relevant variables in those with OUD and chronic pain is important to elucidate MOUD treatment responsiveness.

Taken together, there is a need to understand heterogeneity in MOUD response, particularly in those with chronic pain. Person-centered analyses are suitable as they help identify homogenous subgroups and model their developmental trajectories (Muthén \& Muthén, 
2000). For those on MOUD with chronic pain, person-centered analyses can highlight how important pain mechanisms, such as pain intensity and pain interference, change over time and their differential relationships with key outcome domains, including opioid relapse, psychological functioning, and quality of life. These models can also assess how baseline patient characteristics are associated with pain intensity, pain interference, and their change over time.

The current study utilized data from the POATS clinical trial (Weiss et al., 2011). Prior work using these data has examined pain intensity in relation to relapse among those with chronic pain (Griffin et al., 2016; Messina \& Worley, 2019; Worley et al., 2015, 2017), yet these studies lacked inclusion of outcomes outside of relapse. Baseline demographics, depression, quality of life, and opioid use has also been examined within the entire sample (Griffin et al., 2014, 2015; McHugh et al., 2013; Northrup et al., 2015; Peckham et al., 2020), yet have not been examined among those with chronic pain. To date, only one study has examined depression, pain intensity, and relapse together using person-centered analyses. Vest et al. (2020) used parallel process growth modelling to estimate how changes in depression and pain during treatment contributed to risk for relapse. High levels of depression or high levels of pain throughout treatment were a risk for relapse, particularly during the first three weeks of BUP/NX treatment. Not surprisingly, a substantial proportion of those who endorsed persistent high levels of depression or pain had a diagnosis of chronic pain, suggesting the need for further exploration of these symptoms specifically among this subsample. Pain intensity and pain interference scores were also summed to create a single pain score potentially erasing important nuances between the two domains. Lastly, inclusion of outcomes outside of relapse are necessary to capture overall patient functioning. 
This study aimed to examine profiles of pain interference and pain intensity, and transitions between profiles, estimated in separate models, over the course of 12 weeks of the buprenorphine/naloxone (BUP/NX) treatment using a person-centered statistical approach. Additionally, profiles were examined in relation to several treatment outcomes, including opioid use, depression severity, and mental health quality of life (MH-QOL) while still maintained on BUP/NX (week 12), and two months following a 4-week BUP/NX taper (week 24; see Figure 1 for trial design details). Baseline patient characteristics (age, sex, depression severity, and opioid use) were also examined in relation to profiles and transitions between profiles. Depression severity was examined as a predictor of pain intensity and pain interference profiles given that the indicators used were perceptions of pain in the last 24 hours. We included pain duration as a predictor of profile membership to help further elucidate durability of pain, given the high likelihood that individuals in this sample could be experiencing acute pain related to withdrawal or craving.

It was hypothesized that two profiles would fit the data for pain interference and pain intensity models at each time point (Phase 2 baseline and week 12) that reflected high pain intensity and low pain intensity, and high pain interference and low pain interference. It was also hypothesized that a majority of the sample would transition between the high and low pain interference profiles over the course of treatment, given that BUP/NX and the study treatment have been shown to promote opioid abstinence and lifestyle changes leading to improved quality of life (Volkow et al., 2019; Weiss et al., 2011). Further, the pain intensity profiles would remain stable over the course of treatment, given that BUP/NX has a limited effect on pain intensity (Lazaridou et al., 2020) and the study treatment involved only one session of pain coping skills.

\section{Method}




\section{Participants}

The POATS study recruited participants $(N=653)$ from 10 substance use disorder (SUD) community treatment programs across the Northeast, Northwest, South, and Midwest United States (Weiss et al., 2011). The POATS study used a 2-phase adaptive research design. For the purposes of this study, we focus on Phase $2(n=353)$ during which participants received 12 weeks of BUP/NX maintenance. The sample for the present analysis included participants enrolled in Phase 2 of the study who had endorsed the presence of chronic pain per the Brief Pain Inventory (BPI; $n=194$ ). Two participants dropped out of the study by week 12 , and 74 missed the assessment leaving 118 participants with complete data at week 12 . Another 20 participants missed the following assessment leaving 98 participants with complete data at week 24 .

Inclusion criteria for the larger study required that participants were 18 years or older, met diagnostic criteria for current opioid dependence from prescription opioids based on the Diagnostic and Statistical Manual for Mental Disorders-IV (DSM-IV; APA, 1994), and were willing to be detoxified from opioids. Exclusion criteria included use of heroin for $>4$ days in the past month preceding enrollment at Phase 1 baseline, a lifetime diagnosis of OUD due to heroin alone, had ever injected heroin, a requirement for ongoing pain management with opioids, a prescription of $>40 \mathrm{mg}$ of methadone for pain, or experience of a major acutely painful event in the last 6 months. A major acutely painful event was characterized as a major injury, car accident, or surgery, and did not include pain flare-ups or worsening without a notable causal event.

\section{Procedures}

A full account and rationale of the procedures for the POATS clinical trial can be found in more detail (Weiss et al., 2011). In brief, this study employed a two-phase study design. Upon 
entering Phase 1 of the study, participants completed baseline assessment and were randomized to receive either Standard Medical Management (SMM) or Enhanced Medical Management (EMM). All participants received sublingual BUP/NX for two weeks and were then tapered off over a two-week period and followed for 8 weeks post taper. Doses ranged from $8-32 \mathrm{mg}$ per day. As noted in the primary POATS outcome paper, participants who entered Phase 2 continued to have evidence of OUD. Upon entering Phase 2, participants completed a Phase 2 baseline assessment and were randomized to either SMM or EMM and maintained on BUP/NX for 12 weeks, followed by a taper over a 4-week period. Participants then completed follow up assessments at weeks 16, 20, and 24. The current study included participants in the Phase 2 trial, with a focus on assessments at Phase 1 baseline, and Phase 2 assessments at baseline, week 12, and week 24 (see Figure 1). There were no differences in outcomes based on treatment condition among those with chronic pain at baseline in the primary POATS outcome paper (Weiss et al., 2011), therefore, the data were collapsed across treatment condition in the current study.

\section{Measures}

Diagnosis of OUD, demographic information, chronic pain status, and pain duration were collected upon entering the trial, at the Phase 1 baseline assessment. Assessment of pain interference, pain intensity, depression, and opioid use were collected at the Phase 2 baseline assessment, and monthly throughout Phase 2 of the trial. Assessments of quality of life were collected at the Phase 2 baseline assessment and at Phase 2 week 24.

Pain information. The Brief Pain Inventory (BPI) was used to assess for chronic pain, pain duration, pain interference, and pain intensity (Cleeland, 2009). Chronic pain was assessed by asking respondents if they currently had pain 'other than everyday kinds of pain', and if they selected yes, they were asked how long they have experienced this pain. Pain duration responses 
were categorical, ranging from $<1$ month to $>4$ years. Endorsement of pain, other than everyday kinds of pain, and duration of $\geq 3$ months indicated the presence of chronic pain.

Pain interference was assessed using seven items evaluating the degree to which pain interfered with a number of areas over the last 24 hours on a scale from 0 (does not interfere) to 10 (completed interferes). Domains included general activity, mood, walking ability, normal work, relations with other people, sleep, and enjoyment of life. Pain intensity was assessed using four items asking respondents to rate worst, least, and average pain over the past 24 hours, and current pain on a scale from 0 (no pain) to 10 (pain as bad as you can imagine).

The indicators for the pain interference and pain intensity subscales were treated as continuous, as responses approximated a normal distribution. Internal consistency among the current chronic pain sample was deemed strong across timepoints for the pain interference $(\alpha=$ $.944-.955)$ and pain intensity $(\alpha=.923-.949)$. Each subscale has evidence of adequate validity and reliability in chronic noncancer pain (Tan et al., 2004), and higher scores are robustly associated with poorer outcomes among those with chronic pain (Gerhart et al., 2017).

Mental health quality of life. The Medical Outcomes Study Short-Form 36 (SF-36) was used to assess MH-QOL over the past four weeks. There are 36 Likert-type items that yield two quality of life subscale scores: physical and mental health. The current analyses only used the MH-QOL subscale. Scores range from 0 to 100, with higher scores indicating better quality of life. This measure has evidence of strong validity and reliability in a number of previous samples, including among those with chronic pain (Brazier et al., 1992). Internal consistency was strong across timepoints for the MH-QOL subscales $(\alpha=.920-.938)$.

Depression severity. The Beck Depression Inventory-II (BDI-II) is a 21-item measure used to assess depressive symptoms over the past two weeks using a 4-point Likert-type scale. 
Scores are summed across all items and can range from 0 to 63 , with higher scores indicating worse depression severity. Internal consistency was strong across timepoints $(\alpha=.956-.961)$. The BDI-II has evidence of validity and reliability in chronic pain (Harris \& D'Eon, 2008).

Opioid use. Opioid use was assessed using urine drug screens (UDS), which was analyzed for oxycodone, propoxyphene, illicit methadone, heroin, codeine, and morphine.

Demographic information. Demographic information included age, sex (male or female), race (American Indian/Alaska Native, Asian, Black/African American, Native Hawaiian/Pacific Islander, White, or Other), and ethnicity (of Spanish origin/Latino/Hispanic).

\section{Analysis Plan}

Descriptive statistics and attrition analyses were conducted using SPSS version 26 (IBM Corp., 2019). Attrition analyses assessed for differences among the study variables at the Phase 1 baseline, Phase 2 baseline, week 12, and week 24 assessments between those who had complete data and those who had missing data at each timepoint. Latent variable modeling analyses were conducted using the Mplus software program version 8.2 (Muthén \& Muthén, 2018). The variance covariance matrix was estimated using all available data via the maximum likelihood estimator with robust standard errors.

Latent Profile and Transition Analysis. Latent profiles of pain intensity and interference were derived using an exploratory Latent Profile Analysis (LPA) approach, which is a type of measurement model that derives profiles, or unobservable subgroups, from observable continuous indicators. The pain interference LPA models used the seven items of the BPI pain interference subscale, and the pain intensity LPA models used the four items of the BPI pain intensity subscale. See Supplementary materials for model selection criteria and figures of proposed models. Latent transition analysis (LTA) models were used to examine how individuals 
transitioned between profiles of pain intensity and interference over time. We estimated separate latent profiles at each timepoint, and a transition probability, which is the probability of transitioning between latent profiles between timepoints (Collins \& Lanza, 2009). Measurement invariance of each model was tested to ensure results could be compared across profiles and timepoints (see Supplementary materials for details).

Predictors of Profiles and Transitions. A manual three-step approach was used to test predictors of profile membership and transition between profiles (Asparouhov \& Muthén, 2014). Given the exploratory nature of the LPA models, correction for multiple comparisons were completed using the Benjamini-Hochberg false discovery rate procedure (Benjamini \& Hochberg, 1995, 2000; see Supplementary materials for details). Age, gender, and pain duration, as well as Phase 2 baseline measurements of depression severity and opioid UDS were examined as predictors of profile membership and transition between profiles.

Concurrent and Distal Outcomes. Lastly, profile membership at week 12 was examined in relation to several concurrent (week 12) and distal outcomes (week 24) using the manual BCH method (Bolck et al., 2004) while controlling for Phase 2 baseline assessments of each outcome. Correction for multiple comparisons were completed using the BenjaminiHochberg false discovery rate procedure (Benjamini \& Hochberg, 2000). Outcomes included mental health quality of life, opioid use, and depression severity. Average pain interference and average pain intensity scores at week 24 were also examined (see Supplementary materials for details).

\section{Results}

\section{Descriptive Statistics and Attrition Analyses}


Overall, participants were primarily White (91\%), male (55\%), and ranged in age from 19 to 61 (see Table 1). Over half of the sample had chronic pain for $\geq 4$ years and had a positive UDS for opioids at the Phase 2 baseline assessment. The sample consisted primarily of individuals who had never received treatment (pharmacological or behavioral) in the past for opioids, with less than $20 \%$ ever having received a medication for OUD. Descriptive statistics for the study variables can be found in Table 2. Pain intensity and pain interference at Phase 2 baseline $[r(192)=.80, p<.01]$ and week $12[r(119)=.72, p<.01]$ were significantly correlated. See Supplemental Table 1 for further correlational analyses. Attrition analyses indicated minimal differences between those with complete data and those with missing data at each timepoint. Only those with complete data at week 12 were more likely to endorse higher depressive symptoms $[F(1,194)=5.52, p=.020]$ at Phase 2 baseline, and those with complete data at week 24 were more likely to be younger $[F(1,273)=5.87, p=.016]$ at week 12 .

\section{Latent Profile and Transition Analyses}

Overall, for the both pain interference and pain intensity models, a two-profile LPA solution consistently fit these data best across timepoints with high entropy indicating excellent profile separation. See Supplementary materials for justification of model selection and fit statistics of LPAs (Supplemental Table 2). Figures 2 and 3 present the indicator means for each profile at baseline. The two pain interference profiles at Phase 2 baseline and week 12 represented a high pain interference profile and a low pain interference profile. The same pattern emerged for the pain intensity model, such that a high pain intensity profile and a low pain intensity profile were identified at each timepoint.

Measurement invariance of the unconditional latent transition models were supported. Tests of measurement invariance and details about class proportion shifts across LPA and LTA 
models can be found in the Supplementary materials. Transition probabilities were based on the invariant unconditional models (Table 3). Results indicated individuals who were initially classified in the low pain interference profile at Phase 2 baseline had a low probability of transitioning to high pain interference profile at week 12 (Probability $(\mathrm{P})=.158 ; \mathrm{N}=11,6 \%$ ), and a high probability of remaining in the low pain interference profile at week $12(\mathrm{P}=.842 ; \mathrm{N}=102$, $53 \%)$. Those classified in the high pain interference profile at Phase 2 baseline had a low probability of remaining in the high pain interference profile at week $12(\mathrm{P}=.342 ; \mathrm{N}=17,9 \%)$ and a high probability of transitioning to the low pain interference profile at week $12(\mathrm{P}=.658 ; \mathrm{N}=64$, $32 \%$ ). Similarly, for the pain intensity model, individuals who were initially classified in the low pain intensity profile at Phase 2 baseline had a high probability of remaining in the low pain intensity profile at week $12(\mathrm{P}=.872 ; \mathrm{N}=77,40 \%)$ and a low probability of transitioning to the high pain intensity profile at week $12(\mathrm{P}=.128 ; \mathrm{N}=6,3 \%)$. Those classified in the high pain intensity profile at Phase 2 baseline had a higher probability of transitioning to the low pain intensity profile at week $12(\mathrm{P}=.586 ; \mathrm{N}=80,41 \%)$, and a lower probability of remaining in the high pain intensity profile at week $12(\mathrm{P}=.414 ; \mathrm{N}=31,16 \%)$.

\section{Predictors of Profiles and Transitions}

Using the 3-step approach, predictors of profile membership (Table 4) and transitions between profiles (Table 5) were estimated. The Benjamini-Hochberg false discovery rate procedure was used to evaluate the significance of covariates and outcomes. For the pain interference model, the corrected $p$-value was .007 . For the pain intensity model, the correct $p$ value was .009 .

Pain Interference Model. In the pain interference model, those with higher depression severity at Phase 2 baseline had higher odds of being in the high pain interference profile at both 
timepoints. Age, sex, pain duration, and opioid use were not significant predictors of profile membership at Phase 2 baseline or week 12. There were no significant predictors of transitions between profiles.

Pain Intensity Model. In the pain intensity model, those who were female had higher odds of being in the high pain intensity profile at Phase 2 baseline. Age, pain duration, depression severity, and opioid use were not significant predictors of profile membership at Phase 2 baseline or week 12. There were no significant predictors of transitions between profiles.

\section{Concurrent and Distal Outcomes}

Using the $\mathrm{BCH}$ method and controlling for baseline assessments, concurrent (week 12) and distal (week 24) outcomes were estimated by final profile membership at week 12. Significance was evaluated using a corrected $p$-value (pain interference $p=.007$; pain intensity $p$ $=.009)$. Outcomes included were MH-QOL, depression severity, opioid use, average pain intensity, and average pain interference. Mean comparisons in outcomes by pain interference profile and pain intensity profile at week 12 can be found in Table 5.

Pain Interference Model. Data at week 12 indicated that those in the high pain interference profile had significantly worse MH-QOL and depression severity as compared to those in the low pain interference profile. Those in the high pain interference profile at week 12 continued to have significantly higher pain interference and pain intensity at week 24 as compared to those in the low pain interference profile.

Pain Intensity Model. Those in the high pain intensity profile at week 12 had significantly worse MH-QOL at week 12 as compared to those in the low pain intensity profile. Those in the high pain intensity profile at week 12 had significantly higher pain intensity and higher pain interference at week 24 as compared to those in the low pain intensity profile. 


\section{Discussion}

This study aimed to characterize latent profiles of pain intensity and pain interference, and transitions between profiles, over the course of 12 weeks of BUP/NX maintenance treatment among those with prescription OUD and chronic pain. Concurrent and distal outcomes were analyzed in relation to profile membership at week 12, and several patient characteristics were examined as predictors of profile membership and transitions between profiles. As hypothesized, and consistent with prior research (Tan et al., 2004; Vowles et al., 2017), pain intensity and pain interference were significantly correlated but not entirely overlapping constructs. High and low profiles were identified in the pain interference and pain intensity models at both timepoints, and the majority of individuals were classified in the low pain interference or low pain intensity profile at baseline. Regardless of profile membership at baseline, all individuals had a higher probability of remaining in or transitioning to the low pain interference or low pain intensity profiles over the course of 12 weeks of BUP/NX maintenance treatment.

Overall, individuals in the current study demonstrated improvements in pain intensity and pain interference during BUP/NX maintenance treatment, a finding consistent with prior work from the POATS data (Vest et al., 2020; Worley et al., 2017) and other BUP/NX clinical trials (Chakrabarti et al., 2010; Latif et al., 2019). There are, however, at least four findings that shed new light on this area. First, there was a small subgroup of individuals (15-20\%) whose pain intensity and pain interference remained high or worsened over the course of BUP/NX maintenance treatment. This finding highlights the utility of person-centered analyses in identifying heterogeneous subgroups of patients. It also suggests that, for the majority of patients with prescription OUD and chronic pain, BUP/NX maintenance treatment may be sufficient to improve pain-related functioning. However, there remains a minority of patients who continue to 
demonstrate high pain intensity and pain interference after three months of BUP/NX maintenance treatment. This subgroup also has a more severe clinical profile characterized by worse depressive symptoms and poorer MH-QOL at week 12 . At week 24, there were no significant differences in MH-QOL or depression severity by profile, despite evidence of continued high pain intensity and high pain interference. Continual and frequent assessment of both pain domains are warranted to aid in identifying these individuals during BUP/NX maintenance treatment for whom additional treatment may be needed.

Second, while prior work using the POATS data has indicated that previous pain ratings, high baseline pain, and the experience of highly volatile pain to be associated with relapse (Griffin et al., 2016; Vest et al., 2020; Worley et al., 2015, 2017), the current results add to these findings by indicating that rates of relapse among those with chronic pain did not differ based on high or low pain intensity or pain interference. Taken together, these findings suggest that the negative impacts of pain on relapse may be mitigated following BUP/NX maintenance treatment and medical management.

Third, the analysis of baseline patient characteristics and their relation to pain intensity and pain interference profiles was a unique aspect of this study, in comparison to other studies utilizing this data. Most notably, worse baseline depressive symptoms were predictive of membership in the high pain interference profile at both time points, but not with higher pain intensity at either timepoint. It is important to note that baseline depressive symptoms were associated with transitions in pain intensity profiles (high to low and low to high) at a $p<.05$ level, however this finding did not survive correction for multiple comparisons. Depressive symptoms are clearly relevant in the treatment of OUD in those with chronic pain and remain an important and modifiable treatment target. Further research using intensive longitudinal data 
collection among larger samples is needed to better elucidate the intricate relations between pain intensity, pain interference, and depressive symptoms during BUP/NX maintenance treatment.

Additionally, women were more likely to be in the high pain intensity profile at baseline, although was not predictive of profile membership at week 12. This suggests that, despite reporting higher pain intensity upon treatment entry, women demonstrated an equivalent BUP/NX treatment response in pain intensity as compared to men. This is consistent with prior research using these data, which found women to exhibit worse baseline psychiatric functioning, however, had comparable opioid use outcomes to men (McHugh et al., 2013). Older age was associated with membership in the high pain interference profile at week 12 and transitions in pain intensity profiles (high to low and low to high) at a $p<.05$ level, however this finding did not survive correction for multiple comparisons. Future research investigating the impact of patient characteristics on BUP/NX maintenance treatment responsiveness among larger and more diverse samples remains an important area of further study.

Finally, a higher proportion of the sample endorsed high pain intensity as compared to high pain interference at both timepoints suggesting that some did not perceive their pain as significantly interfering with important areas of life. Given that POATS recruited from SUD community treatment programs, it is possible that they may have perceived other problems, such as substance use, as interfering in these domains rather than pain. This supposition may also explain the minimal differences between pain interference profiles in the outcome and transition analyses. It is possible that pain interference may not be an important mechanism among those presenting to SUD clinics and early in MOUD treatment where substance use is more likely to be perceived as the primary barrier to functioning. It remains possible that pain interference is a 
barrier to functioning later in BUP/NX maintenance treatment, at which point, it may become a more robust indicator of relapse or overall functioning.

\section{Limitations}

There are several limitations that should be taken into consideration when interpreting these results. First, there is no gold standard model fit index, therefore, model selection is based to some degree on existing guidelines and judgement of investigators. Second, the sample size was relatively small for the current analyses which may have impacted our ability to detect additional, smaller classes. Further work with larger sample sizes is needed. Third, all models are probabilistic and there is always the chance of misclassification. Entropy, a measure of misclassification, ranged from .767 to .960 suggesting that anywhere from 4-23\% of participants may have been misclassified in the models. Fourth, while attrition analyses indicated minimal differences between those with missing and complete data at each timepoint, we are not able to describe the extent to which attrition had an impact on the study results. Fifth, the current models conceptualized several variables as predictors of latent profiles, but it may be the case that these variables are also outcomes of high pain intensity and interference. Future work using intensive longitudinal data could be used to gain a better understanding of how these processes are mutually related over time. Sixth, the generalizability of findings is limited by characteristics of the sample, who were primarily White and of younger age, and further examination in more diverse samples is needed. Moreover, all participants received BUP/NX prior to Phase 2 of POATS, thus findings may not generalize to those who are completely treatment naïve.

Finally, average pain intensity and pain interference scores were typically in the mild to moderate range (i.e., 3-4 out of 10) at baseline and decreased over time. These scores are descriptively lower than more traditional chronic pain samples (i.e. 6-7 out of 10; Nicholas et al., 
2019). This difference may be due to two reasons. First, it is possible that the first question of the BPI, which was used to categorize individuals as having chronic pain in these data, may be overly sensitive (Dennis et al., 2016). Second, there may be selection bias, as those endorsing more severe chronic pain may have received treatment in specialty pain clinics rather than SUD clinics or may have had limited access to treatment more broadly due to limited physical capabilities or inadequate resources. Given these limitations, it should be noted that the findings depicted in the current study are not definitive in nature. While the current study may offer a more precise characterization of associations between latent pain profiles, patient characteristics, and psychopathology, there will likely be a number of deviations from the current findings in future research and real-world clinical practice.

\section{Future Directions}

There are several important implications. First, while BUP/NX maintenance and medical management may be effective for the treatment of prescription OUD and chronic pain (Daitch et al., 2014), there remains a small subgroup who continue to exhibit high pain intensity and high pain interference three months following treatment. These individuals are likely to experience worse mood and quality of life during BUP/NX maintenance, and persistently high pain intensity and interference following a BUP/NX taper. Further medical and psychological treatment, particularly focused on pain coping, craving, and depression, may be warranted for these individuals.

Second, further integration of behavioral treatments and their potential role in co-morbid OUD and chronic pain is deserving of additional study. While one of the POATS study arms included pain coping skills training, this was only a small component of the behavioral therapy (Opioid Drug Counseling) and the efficacy of such integration is unclear across studies, 
including the original POATS outcome study (Ilgen et al., 2020; Messina \& Worley, 2019;

Weiss et al., 2011). One avenue of additional study may be an explicit focus on two mechanisms.

First, reducing pain interference, given its importance to overall functioning and quality of life, and second, altering responses to craving, given its important role in mediating between pain intensity and relapse (Northrup et al., 2015; Tsui et al., 2016). In particular, mindfulness-based interventions and Acceptance and Commitment Therapy (ACT) may be particularly well suited to address several presenting issues given their transdiagnostic framework (Hayes et al., 2012; Witkiewitz et al., 2014). A recent pilot study of an integrated mindfulness and ACT treatment successfully reduced pain interference and opioid misuse in veterans with chronic pain (Vowles et al., 2020). Further, two studies of mindfulness indicated positive treatment outcomes in these same two domains, using an approach called Mindfulness Oriented Recovery Enhancement (Garland et al., 2014, 2019), as did a recent pilot study of Cognitive-Behavioral Therapy (CBT) in opioid use (Barry et al., 2019). Further work is needed, particularly in relation to integrated treatments of OUD and chronic pain.

Third, observational studies of chronic pain among patients maintained on MOUD are needed to determine if patients experience changes to their chronic pain status and severity over a longer period of time. For example, a previous POATS study found 53\% of patients reported variability in their chronic pain status over a 3.5-year period (McDermott et al., 2019), which suggests the reduction in chronic pain severity in the present results may not persist. Given this, it is important to continually monitor pain intensity and pain interference even if patients have experienced improvements in pain-related functioning during BUP/NX treatment. If chronic pain severity does worsen, interventions targeting pain coping, craving, and depression, may help prevent relapse and improve overall functioning and quality of life. 


\section{References}

Andersson, H. I. (2004). The course of non-malignant chronic pain: A 12-year follow-up of a cohort from the general population. European Journal of Pain, 8, 47-53. https://doi.org/10.1016/S1090-3801(03)00064-8

APA. (1994). Diagnostic and Statistical Manual of Mental Disorders (4th ed.).

Asparouhov, T., \& Muthén, B. (2014). Auxiliary variables in mixture modeling: Three-step approaches using Mplus. Mplus Web Notes, 8, 1-51.

https://doi.org/10.1080/10705511.2014.915181

Barry, D. T., Beitel, M., Cutter, C. J., Fiellin, D. A., Kerns, R. D., Moore, B. A., Oberleitner, L., Madden, L. M., Liong, C., Ginn, J., \& Schottenfeld, R. S. (2019). An evaluation of the feasibility, acceptability, and preliminary efficacy of cognitive-behavioral therapy for opioid use disorder and chronic pain. Drug and Alcohol Dependence, 194, 460-467. https://doi.org/10.1016/j.drugalcdep.2018.10.015

Benjamini, Y., \& Hochberg, Y. (1995). Controlling the False Discovery Rate: A Practical and Powerful Approach to Multiple Testing. Journal of the Royal Statistical Society, 57(1), $289-300$.

Benjamini, Y., \& Hochberg, Y. (2000). On the adaptive control of the false discovery rate in multiple testing with independent statistics. Journal of Educational and Behavioral Statistics, 25(1), 60-83. https://doi.org/10.3102/10769986025001060

Bolck, A., Croon, M., \& Hagenaars, J. (2004). Estimating latent structure models with categorical variables: One-step versus three-step estimators. Political Analysis, 12(1), 3-27. https://doi.org/10.1093/pan/mph001

Bray, J. W., Aden, B., Eggman, A. A., Hellerstein, L., Wittenberg, E., Nosyk, B., Stribling, J. C., 
\& Schackman, B. R. (2017). Quality of life as an outcome of opioid use disorder treatment: A systematic review. Journal of Substance Abuse Treatment, 76, 88-93. https://doi.org/10.1016/j.jsat.2017.01.019

Brazier, J. E., Harper, R., Jones, N. M., O’Cathain, A., Thomas, K. J., Usherwood, T., \& Westlake, L. (1992). Validating the SF-36 health survey questionnaire: New outcome measure for primary care. BMJ, 305(6846), 160-164. https://doi.org/10.1136/bmj.305.6846.160

Centers for Disease Control and Prevention. (2018). 2018 Annual Surveillance Drug-Related Risks and Outcomes - United States. In Surveillance Special Report.

Chakrabarti, A., Woody, G. E., Griffin, M. L., Subramaniam, G., \& Weiss, R. D. (2010). Predictors of buprenorphine-naloxone dosing in a 12-week treatment trial for opioiddependent youth: Secondary analyses from a NIDA Clinical Trials Network study. Drug and Alcohol Dependence, 107(2-3), 253-256. https://doi.org/10.1016/j.drugalcdep.2009.10.014

Cleeland, C. S. (2009). The Brief Pain Inventory: User Guide. https://www.mdanderson.org/content/dam/mdanderson/documents/Departments-andDivisions/Symptom-Research/BPI_UserGuide.pdf

Collins, L. M., \& Lanza, S. T. (2009). Latent class and latent transition analysis for applications in the social, behavioral and health sciences. John Wiley \& Sons, Inc. https://doi.org/10.1002/9780470567333

Daitch, D., Daitch, J., Novinson, D., Frey, M., Mitnick, C., \& Pergolizzi, J. (2014). Conversion from high-dose full-opioid agonists to sublingual buprenorphine reduces pain scores and improves quality of life for chronic pain patients. Pain Medicine, 15(12), 2087-2094. 
https://doi.org/10.1111/pme.12520

Dennis, B. B., Bawor, M., Naji, L., Chan, C. K., Varenbut, J., Paul, J., Varenbut, M., Daiter, J., Plater, C., Pare, G., Marsh, D. C., Worster, A., Desai, D., Thabane, L., \& Samaan, Z. (2015). Impact of chronic pain on treatment prognosis for patients with opioid use disorder: A systematic review and meta-analysis. Substance Abuse: Research and Treatment, 9, 5980. https://doi.org/10.4137/SART.S30120

Dennis, B. B., Roshanov, P. S., Bawor, M., Paul, J., Varenbut, M., Daiter, J., Plater, C., Pare, G. G., Marsh, D. C., Worster, A., Desai, D., Thabane, L., Samaan, Z., March, D. C., Worster, A., Desai, D., Thabane, L., \& Samaan, Z. (2016). Usefulness of the Brief Pain Inventory in patients with opioid addiction receiving methadone maintenance treatment. Pain Physician, 19(1), E181-E195.

Dunn, K. E., Brooner, R. K., \& Clark, M. R. (2014). Severity and interference of chronic pain in methadone-maintained outpatients. Pain Medicine, 15, 1540-1548.

Dunn, K. E., Finan, P. H., Tompkins, D. A., Fingerhood, M., \& Strain, E. C. (2015). Characterizing pain and associated coping strategies in methadone and buprenorphinemaintained patients. Drug and Alcohol Dependence, 157(2015), 143-149. https://doi.org/10.1016/j.drugalcdep.2015.10.018

Dworkin, R. H., Turk, D. C., Wyrwich, K. W., Beaton, D., Cleeland, C. S., Farrar, J. T., Haythornthwaite, J. A., Jensen, M. P., Kerns, R. D., Ader, D. N., Brandenburg, N., Burke, L. B., Cella, D., Chandler, J., Cowan, P., Dimitrova, R., Dionne, R., Hertz, S., Jadad, A. R., ... Zavisic, S. (2008). Interpreting the clinical importance of treatment outcomes in chronic pain clinical trials: IMMPACT recommendations. Journal of Pain, 9(2), 105-121. https://doi.org/10.1016/j.jpain.2007.09.005 
Edwards, R. R., Dworkin, R. H., Sullivan, M. D., Turk, D. C., \& Wasan, A. D. (2016). The role of psychosocial processes in the development and maintenance of chronic pain disorders. Journal of Pain, 17(9), T70-T92. https://doi.org/10.1016/j.jpain.2016.01.001

Garland, E. L., Hanley, A. W., Kline, A., \& Cooperman, N. A. (2019). Mindfulness-Oriented Recovery Enhancement reduces opioid craving among individuals with opioid use disorder and chronic pain in medication assisted treatment: Ecological momentary assessments from a stage 1 randomized controlled trial. Drug and Alcohol Dependence, 203(July), 61-65. https://doi.org/10.1016/j.drugalcdep.2019.07.007

Garland, E. L., Manusov, E. G., Froeliger, B., Kelly, A., Williams, J. M., \& Howard, M. O. (2014). Mindfulness-oriented recovery enhancement for chronic pain and prescription opioid misuse: Results from an early-stage randomized controlled trial. Journal of Consulting and Clinical Psychology, 82(3), 448-459. https://doi.org/10.1037/a0035798

Gerhart, J. I., Burns, J. W., Post, K. M., Smith, D. A., Porter, L. S., Burgess, H. J., Schuster, E., Buvanendran, A., Fras, A. M., \& Keefe, F. J. (2017). Relationships between sleep quality and pain-related factors for people with chronic low back pain: Tests of reciprocal and time of day effects. Annals of Behavioral Medicine, 51(3), 365-375. https://doi.org/10.1007/s12160-016-9860-2

Griffin, M. L., Bennett, H. E., Fitzmaurice, G. M., Hill, K. P., Provost, S. E., \& Weiss, R. D. (2015). Health-related quality of life among prescription opioid-dependent patients: Results from a multi-site study. American Journal on Addictions, 24(4), 308-314. https://doi.org/10.1111/ajad.12188

Griffin, M. L., Dodd, D. R., Potter, J. S., Rice, L. S., Dickinson, W., Sparenborg, S., \& Weiss, R. D. (2014). Baseline characteristics and treatment outcomes in prescription opioid dependent 
patients with and without co-occurring psychiatric disorder. Am J Drug Alcohol Abuse, 40(2), 157-162. https://doi.org/10.3109/00952990.2013.842241.Baseline

Griffin, M. L., McDermott, K. A., McHugh, R. K., Fitzmaurice, G. M., Jamison, R. N., \& Weiss, R. D. (2016). Longitudinal association between pain severity and subsequent opioid use in prescription opioid dependent patients with chronic pain. Drug and Alcohol Dependence, 163, 216-221. https://doi.org/10.1016/j.drugalcdep.2016.04.023

Harris, C. A., \& D’Eon, J. L. (2008). Psychometric properties of the Beck Depression InventorySecond Edition (BDI-II) in individuals with chronic pain. Pain, 137(3), 609-622. https://doi.org/10.1016/j.pain.2007.10.022

Hayes, S. C., Strosahl, K. D., \& Wilson, K. G. (2012). Acceptance and Commitment Therapy: The process and practice of mindful change (2nd ed.). Guilford Press.

Hser, Y. I., Mooney, L. J., Saxon, A. J., Miotto, K., Bell, D. S., \& Huang, D. (2017). Chronic pain among patients with opioid use disorder: Results from electronic health records data. Journal of Substance Abuse Treatment, 77, 26-30. https://doi.org/10.1016/j.jsat.2017.03.006

IBM Corp. (2019). IBM SPSS Statistics for Windows (26.0). IBM Corp.

Ilgen, M.A., Coughlin, L. N., Bohnert, A. S. B., Chermack, S., Price, A., Kim, H. M., Jannausch, M., \& Blow, F. C. (2020). Efficacy of a psychosocial pain management intervention for men and women with substance use disorders and chronic pain: A randomized clinical trial. JAMA Psychiatry, 77(12), 1225-1234. https://doi.org/10.1001/jamapsychiatry.2020.2369 Ilgen, Mark A., Trafton, J. A., \& Humphreys, K. (2006). Response to methadone maintenance treatment of opiate dependent patients with and without significant pain. Drug and Alcohol Dependence, 82(3), 187-193. https://doi.org/10.1016/j.drugalcdep.2005.09.005 
Jamison, R. N., Kauffman, J., \& Katz, N. P. (2000). Characteristics of methadone maintenance patients with chronic pain. Journal of Pain and Symptom Management, 19(1), 53-62. https://doi.org/10.1016/S0885-3924(99)00144-X

Jones, J. D., Vogelman, J. S., Luba, R., Mumtaz, M., \& Comer, S. D. (2017). Chronic pain and opioid abuse: Factors associated with health-related quality of life. American Journal on Addictions, 26(8), 815-821. https://doi.org/10.1111/ajad.12637

Landmark, T., Dale, O., Romundstad, P., Woodhouse, A., Kaasa, S., \& Borchgrevink, P. C. (2018). Development and course of chronic pain over 4 years in the general population: The HUNT pain study. European Journal of Pain (United Kingdom), 22(9), 1606-1616. https://doi.org/10.1002/ejp.1243

Latif, Z. e. H., Solli, K. K., Opheim, A., Kunoe, N., Benth, J., Krajci, P., Sharma-Haase, K., \& Tanum, L. (2019). No increased pain among opioid-dependent individuals treated with extended-release naltrexone or buprenorphine-naloxone: A 3-month randomized study and 9-month open-treatment follow-up study. American Journal on Addictions, 28(2), 77-85. https://doi.org/10.1111/ajad.12859

Lazaridou, A., Paschali, M., Edwards, R. R., \& Gilligan, C. (2020). Is buprenorphine effective for chronic pain? A systematic review and meta-analysis. Pain Medicine, In press, 1-9. https://doi.org/10.1093/pm/pnaa089

McDermott, K. A., Griffin, M. L., McHugh, R. K., Fitzmaurice, G. M., Jamison, R. N., Provost, S. E., \& Weiss, R. D. (2019). Long-term naturalistic follow-up of chronic pain in adults with prescription opioid use disorder. Drug and Alcohol Dependence, 205(June). https://doi.org/10.1016/j.drugalcdep.2019.107675

McHugh, R. K., Devito, E. E., Dodd, D., Carroll, K. M., Potter, J. S., Greenfield, S. F., Smith, 
H., Weiss, R. D., Connery, H. S., \& Weiss, R. D. (2013). Gender differences in a clinical trial for prescription opioid dependence. Journal of Substance Abuse Treatment, 45(1), 3843. https://doi.org/10.1016/j.jsat.2012.12.007.Gender

Messina, B. G., \& Worley, M. J. (2019). Effects of craving on opioid use are attenuated after pain coping counseling in adults with chronic pain and prescription opioid addiction. Journal of Consulting and Clinical Psychology, 87(10), 918-926. https://doi.org/10.1037/ccp0000399

Mun, C. J., Beitel, M., Oberleitner, L., Oberleitner, D. E., Madden, L. M., Bollampally, P., \& Barry, D. T. (2019). Pain catastrophizing and pain acceptance are associated with pain severity and interference among methadone-maintained patients. Journal of Clinical Psychology, 75(12), 2233-2247. https://doi.org/10.1002/jclp.22842

Muthén, B. O., \& Muthén, L. K. (2000). Integrating person-centered and variable-centered analyses: Growth mixture modeling with latent trajectory classes. Alcoholism: Clinical and Experimental Research, 24(6), 882-891. https://doi.org/10.1111/j.15300277.2000.tb02070.x

Muthén, L. K., \& Muthén, B. O. (2018). Mplus users guide (Version 8.2). Muthén \& Muthén. Ngo, B., Liebschutz, J. M., Cheng, D. M., Colasanti, J. A., Merlin, J. S., Armstrong, W. S., Forman, L. S., Lira, M. C., Samet, J. H., del Rio, C., \& Tsui, J. I. (2021). Hazardous alcohol use is associated with greater pain interference and prescription opioid misuse among persons living with HIV and chronic pain. BMC Public Health, 21(1), 1-9. https://doi.org/10.1186/s12889-021-10566-6

Nicholas, M. K., Costa, D. S. J., Blanchard, M., Tardif, H., Asghari, A., \& Blyth, F. M. (2019). Normative data for common pain measures in chronic pain clinic populations. Pain, 160(5), 
1156-1165. https://doi.org/10.1097/j.pain.0000000000001496

Northrup, T. F., Stotts, A. L., Green, C., Potter, J. S., Marino, E. N., Walker, R., Weiss, R. D., \& Trivedi, M. (2015). Opioid withdrawal, craving, and use during and after outpatient buprenoprhine stabilization and taper: A discrete survival and growth mixture model. Addictive Behaviors, 41(1), 20-28. https://doi.org/10.1038/jid.2014.371

Peckham, A. D., Griffin, M. L., McHugh, R. K., \& Weiss, R. D. (2020). Depression history as a predictor of outcomes during buprenorphine-naloxone treatment of prescription opioid use disorder. Drug and Alcohol Dependence, 213(June). https://doi.org/10.1016/j.drugalcdep.2020.108122

Tan, G., Jensen, M. P., Thornby, J. I., \& Shanti, B. F. (2004). Validation of the brief pain inventory for chronic nonmalignant pain. Journal of Pain, 5(2), 133-137. https://doi.org/10.1016/j.jpain.2003.12.005

Tiffany, S. T., Friedman, L., Greenfield, S. F., Hasin, D. S., \& Jackson, R. (2012). Beyond drug use: A systematic consideration of other outcomes in evaluations of treatments for substance use disorders. Addiction, 107(4), 709-718. https://doi.org/10.1111/j.13600443.2011.03581.x

Tsui, J. I., Lira, M. C., Cheng, D. M., Winter, M. R., Alford, D. P., Liebschutz, J. M., Edwards, R. R., \& Samet, J. H. (2016). Chronic pain, craving, and illicit opioid use among patients receiving opioid agonist therapy. Drug and Alcohol Dependence, 166, 26-31. https://doi.org/10.1016/j.drugalcdep.2016.06.024

Vest, N. A., McPherson, S., Burns, G. L., \& Tragesser, S. (2020). Parallel modeling of pain and depression in prediction of relapse during buprenorphine and naloxone treatment: A finite mixture model. Drug and Alcohol Dependence, 209(October 2019), 1-8. 
https://doi.org/10.1016/j.drugalcdep.2020.107940

Volkow, N. D., Jones, E. B., Einstein, E. B., \& Wargo, E. M. (2018). Prevention and treatment of opioid misuse and addiction. JAMA Psychiatry, 76(2), 208-216. https://doi.org/10.1001/jamapsychiatry.2018.3126

Volkow, N. D., Jones, E. B., Einstein, E. B., \& Wargo, E. M. (2019). Prevention and treatment of opioid misuse and addiction: A review. JAMA Psychiatry, 76(2), 208-216. https://doi.org/10.1001/jamapsychiatry.2018.3126

Vowles, K. E., McEntee, M. L., Julnes, P. S., Frohe, T., Ney, J. P., \& van der Goes, D. N. (2015). Rates of opioid misuse, abuse, and addiction in chronic pain: A systematic review and data synthesis. Pain, 156(4), 569-576. https://doi.org/10.1097/01.j.pain.0000460357.01998.f1

Vowles, K. E., Witkiewitz, K., Cusack, K. J., Gilliam, W. P., Cardon, K. E., Bowen, S., Edwards, K. A., McEntee, M. L., \& Bailey, R. W. (2019). Integrated behavioral treatment for Veterans with co-morbid chronic pain and hazardous opioid use: A randomized controlled pilot trial. The Journal of Pain, 2019. https://doi.org/10.1016/j.jpain.2019.11.007

Vowles, K. E., Witkiewitz, K., Levell, J., Sowden, G., \& Ashworth, J. (2017). Are reductions in pain intensity and pain-related distress necessary? An analysis of within-treatment change trajectories in relation to improved functioning following interdisciplinary acceptance and commitment therapy for adults with chronic pain. Journal of Consulting and Clinical Psychology, 85(2), 87-98. https://doi.org/10.1037/ccp0000159

Wachholtz, A., Foster, S., \& Cheatle, M. (2015). Psychophysiology of pain and opioid use: Implications for managing pain in patients with an opioid use disorder. Drug and Alcohol Dependence, 146(1), 1-6. https://doi.org/10.1016/j.drugalcdep.2014.10.023 
Weiss, R. D., Potter, J. S., Fiellin, D. A., Byrne, M., Connery, H. S., Dickinson, W., Gardin, J., Griffin, M. L., Gourevitch, M. N., Haller, D. L., Hasson, A. L., Huang, Z., Jacobs, P., Kosinski, A. S., Lindblad, R., McCance-Katz, E. F., Provost, S. E., Selzer, J., Somoza, E. C., ... Ling, W. (2011). Adjunctive counseling during brief and extended buprenorphinenaloxone treatment for prescription opioid dependence: A 2-phase randomized controlled trial. Archives of General Psychiatry, 68(12), 1238-1246. https://doi.org/10.1021/ol502971e

Witkiewitz, K., Bowen, S., Harrop, E. N., Douglas, H., Enkema, M., \& Sedgwick, C. (2014). Mindfulness-based treatment to prevent addictive behavior relapse: Theoretical models and hypothesized mechanisms of change. Substance Use and Misuse, 49(5), 513-524. https://doi.org/10.3109/10826084.2014.891845

Wollschlaeger, B. A., Willson, T. M., Montejano, L. B., Ronquest, N. A., \& Nadipelli, V. R. (2017). Characteristics and treatment patterns of US commercially insured and Medicaid patients with opioid dependence or abuse. Journal of Opioid Management, 13(4), 207-220. https://doi.org/10.5055/jom.2017.0389

Worley, M. J., Heinzerling, K. G., Shoptaw, S., \& Ling, W. (2015). Pain volatility and prescription opioid addiction treatment outcomes in patients with chronic pain. Experimental and Clinical Psychopharmacology, 23(6), 428-435. https://doi.org/10.1037/pha0000039

Worley, M. J., Heinzerling, K. G., Shoptaw, S., \& Ling, W. (2017). Volatility and change in chronic pain severity predict outcomes of treatment for prescription opioid addiction. Addiction, 112(7), 1202-1209. https://doi.org/10.1111/add.13782 


\section{Appendix}

Data Transparency Statement:

All authors attest that the data reported in this manuscript were obtained from publicly available data, Prescription Opioid Addiction Treatment Study (OATS). A comprehensive bibliography of journal articles, working papers, conference presentations, and dissertations using the POATS data is available here. Manuscripts 1,2,5,7, and 8 (published) focuses on pain intensity and depression; while manuscripts 9, 11,12, 13, 14, 15, 17, 20, 23, 25, 28 (published) focuses on opioid use, and manuscripts 25 and 26 (published) focuses on gender. The current manuscript focuses on pain interference, pain intensity, depression, mental health quality of life, opioid use, age, and gender. Of note, one author has 8 manuscripts that are either published or in press using this data. All other authors do not have any published or in press manuscripts using this data. 


\section{Tables}

Table 1. Sample demographic characteristics.

\begin{tabular}{|c|c|c|}
\hline Measure & $\mathrm{N}$ & Mean (SD) or \% \\
\hline Age & 194 & $35.3(10.4)$ \\
\hline \multicolumn{3}{|l|}{ Sex } \\
\hline Male & 107 & $55 \%$ \\
\hline Female & 87 & $44 \%$ \\
\hline \multicolumn{3}{|l|}{ Ethnicity/Race* } \\
\hline White & 177 & $91 \%$ \\
\hline Hispanic/Latinx & 9 & $5 \%$ \\
\hline Black/African American & 5 & $3 \%$ \\
\hline Asian/Native Hawaiian/Pacific Islander & 2 & $1 \%$ \\
\hline American Indian/Alaska Native & 8 & $4 \%$ \\
\hline Other & 6 & $3 \%$ \\
\hline \multicolumn{3}{|l|}{ Pain Duration } \\
\hline 3 mo to $<2$ years & 35 & $18 \%$ \\
\hline 2 to $<4$ years & 54 & $28 \%$ \\
\hline$\geq 4$ years & 105 & $54 \%$ \\
\hline \multicolumn{3}{|l|}{ Ever been in treatment for opiates } \\
\hline No & 132 & $68 \%$ \\
\hline Yes & 62 & $32 \%$ \\
\hline Received Methadone & 21 & $11 \%$ \\
\hline Received Buprenorphine & 11 & $6 \%$ \\
\hline
\end{tabular}

*Does not add to 194 as participants were able to select all that apply. 
Table 2. Descriptive statistics of all study variables at all study timepoints.

\begin{tabular}{|c|c|c|c|}
\hline Variable & Phase 2 Baseline & Week 12 & Week 24 \\
\hline & $\mathrm{N}=194$ & $\mathrm{~N}=118$ & $\mathrm{~N}=98$ \\
\hline & Mean (SD) & Mean (SD) & Mean (SD) \\
\hline or N (\%) & or N (\%) & or N (\%) \\
\hline BPI Pain Interference Subscale & $3.93(2.88)$ & $2.48(2.24)$ & $2.57(2.33)$ \\
\hline General Activity & $4.40(3.28)$ & $2.97(2.77)$ & $2.88(2.76)$ \\
\hline Mood & $4.36(3.35)$ & $2.69(2.59)$ & $2.54(2.55)$ \\
\hline Walking Ability & $3.20(2.94)$ & $2.33(2.47)$ & $2.18(2.51)$ \\
\hline Normal Work & $3.79(3.12)$ & $2.51(2.48)$ & $2.52(2.54)$ \\
\hline Relations with Others & $3.26(3.21)$ & $1.68(2.11)$ & $1.95(2.43)$ \\
\hline Sleep & $4.55(3.48)$ & $2.92(3.02)$ & $3.35(2.90)$ \\
\hline Enjoyment of Life & $3.98(3.39)$ & $2.24(2.59)$ & $2.54(2.69)$ \\
\hline BPI Pain Intensity Subscale & $4.21(2.55)$ & $2.93(1.98)$ & $2.90(2.05)$ \\
\hline Worst pain & $5.73(3.04)$ & $4.28(2.66)$ & $4.16(2.60)$ \\
\hline Least pain & $3.01(2.51)$ & $2.09(1.97)$ & $2.00(1.84)$ \\
\hline Average pain & $4.09(2.39)$ & $2.86(1.91)$ & $2.97(2.09)$ \\
\hline Pain now & $4.01(2.99)$ & $2.49(2.18)$ & $2.46(2.18)$ \\
\hline Covariates ${ }^{a}$ and Distal Outcomes & & & \\
\hline Depression Severity & $18.30(13.08)$ & $8.97(10.54)$ & $9.76(10.77)$ \\
\hline Opioid Use ${ }^{b, c}$ & $57.29(20.43)$ & $67.00(19.22)$ & $64.04(18.79)$ \\
\hline Mental Health QOL & & $24(21 \%)$ & $37(40 \%)$ \\
\hline
\end{tabular}

Note. $\mathrm{BPI}=$ Brief Pain Inventory; $\mathrm{QOL}=$ Quality of life. ${ }^{\mathrm{a}}=$ Age and sex were also used as covariates and are described in Table $1 .{ }^{b}=$ Number of positive urine drug screen. ${ }^{\mathrm{c}}=$ Includes oxycodone, propoxyphene, illicit methadone, heroin, codeine, and morphine. 
Table 3. Transition probabilities from Phase 2 baseline to week 12 for the unconditional pain interference and pain intensity models.

\begin{tabular}{lcc}
\hline Phase 2 Baseline Profile & \multicolumn{2}{c}{ Week 12 Profile } \\
\hline Pain Interference & Low interference & High interference \\
Low interference $(\mathrm{N}=113 ; 58 \%)$ & $(\mathrm{N}=166 ; 86 \%)$ & $(\mathrm{N}=28 ; 14 \%)$ \\
High interference $(\mathrm{N}=81 ; 42 \%)$ & .842 & .158 \\
Pain Intensity & .658 & .342 \\
& Low intensity & High intensity \\
Low intensity $(\mathrm{N}=83 ; 43 \%)$ & $(\mathrm{N}=157 ; 81 \%)$ & $(\mathrm{N}=37 ; 19 \%)$ \\
High intensity $(\mathrm{N}=111 ; 57 \%)$ & .872 & .128 \\
\end{tabular}

Note. Entropy was .806 and .767 for the unconditional pain interference model and pain intensity model, respectively. Final profile counts and proportions are based on the most likely latent profile membership. 
Table 4. Predictors of profile membership at Phase 2 baseline and week 12 for the pain interference and pain intensity models.

\begin{tabular}{llrrr}
\hline Predictor $^{\mathrm{a}}$ & \multicolumn{2}{c}{ Phase 2 Baseline } & \multicolumn{2}{c}{ Week 12 } \\
\hline & OR & $95 \%$ CI & OR & $95 \%$ CI
\end{tabular}

High pain interference

$\begin{array}{lcccc}\text { Age } & 1.01 & .98,1.05 & 1.05 & 1.01,1.10 \\ \operatorname{Sex}^{\mathrm{d}} & 1.84 & .86,3.92 & 2.01 & .62,6.50 \\ \text { Pain Duration } & 1.61 & .93,2.76 & 1.70 & .92,3.15 \\ \text { Depression severity } & 1.09 * & 1.05,1.13 & 1.06 * & 1.02,1.10 \\ \text { Opioid use } & .99 & .47,2.76 & 4.18 & .72,24.38\end{array}$

High pain intensity

$\begin{array}{lcccc}\text { Age } & 1.00 & .97,1.03 & .99 & .94,1.04 \\ \operatorname{Sex}^{\mathrm{d}} & 2.73 * & 1.28,5.80 & .95 & .31,2.93 \\ \text { Pain Duration } & 1.41 & .95,2.09 & 1.48 & .86,2.55 \\ \text { Depression severity } & 1.03 & .99,1.06 & 1.01 & .97,1.05 \\ \text { Opioid use }^{\mathrm{e}} & 2.00 & .95,4.18 & 2.44 & .72,8.32\end{array}$

Note. ${ }^{*}=$ Significant based on corrected $p$-value for multiple comparisons (pain interference model: $p=.007$; pain intensity model: $p=.009$ ). Reference group is the low pain interference/intensity profile. ${ }^{\mathrm{a}}=$ Age, sex, and pain duration were assessed at Phase 1 baseline, and depression and opioid/opiate use were assessed at Phase 2 baseline. $\mathrm{OR}=$ Odds ratio. $95 \% \mathrm{CI}=95 \%$ confidence interval; lower bound, upper bound. ${ }^{\mathrm{d}}=$ Male $=0$, female $=1 .^{\mathrm{e}}=$ No use $=0$, use $=1$. Entropy for the full conditional model was .85 and .80 for the pain interference model for the pain intensity model, respectively. 
Table 5. Predictors of transitions between profiles at Phase 2 baseline and week 12 for the pain interference and pain intensity models.

\begin{tabular}{|c|c|c|c|}
\hline Transition Pattern & Predictor $^{\mathrm{a}}$ & $\mathrm{OR}^{\mathrm{b}}$ & $95 \% \mathrm{CI}^{\mathrm{c}}$ \\
\hline \multicolumn{4}{|l|}{ Pain interference } \\
\hline \multirow[t]{3}{*}{ High - High $^{1}$} & Age & .99 & $.90,1.10$ \\
\hline & $\operatorname{Sex}^{\mathrm{d}}$ & .77 & $.06,10.11$ \\
\hline & Depression severity & 1.02 & $.94,1.11$ \\
\hline \multirow[t]{3}{*}{ Low - High $^{2}$} & Age & 1.01 & $.91,1.11$ \\
\hline & $\operatorname{Sex}^{\mathrm{d}}$ & 1.30 & $.10,17.05$ \\
\hline & Depression severity & .98 & $.90,1.06$ \\
\hline \multicolumn{4}{|l|}{ Pain intensity } \\
\hline \multirow[t]{3}{*}{ High - High $^{1}$} & Age & .90 & $.81, .99$ \\
\hline & $\operatorname{Sex}^{\mathrm{d}}$ & 1.17 & $.03,53.20$ \\
\hline & Depression severity & .91 & $.82, .99$ \\
\hline \multirow[t]{3}{*}{ Low - High $^{2}$} & Age & 1.11 & $1.01,1.24$ \\
\hline & $\operatorname{Sex}^{\mathrm{d}}$ & .85 & $.02,38.80$ \\
\hline & Depression severity & 1.11 & $1.01,1.22$ \\
\hline
\end{tabular}

Note. $*$ Significant based on corrected $p$-value for multiple comparisons (pain interference model: $p=.007$; pain intensity model: $p=.009$ ). ${ }^{\mathrm{a}}=$ Age and sex were assessed at Phase 1 baseline, and depression was assessed at Phase 2 baseline. ${ }^{b}=$ Odds ratio. ${ }^{c}=95 \%$ confidence interval; lower bound, upper bound. ${ }^{\mathrm{d}}=$ Male $=0$, female $=1 .{ }^{1}=$ Reference group is High - Low . ${ }^{2}=$ Reference group is Low - Low. Opioid use was not examined in relation to transitions in either model due to convergence errors, likely due to the small sample size. 
Table 6. Differences in outcome variables by profile membership at week 12 for the pain interference and pain intensity models.

\begin{tabular}{|c|c|c|c|c|}
\hline & \multicolumn{2}{|c|}{ Week 12} & \multicolumn{2}{|c|}{ Week 24} \\
\hline Outcome & $t$ & $95 \% \mathrm{CI}$ & $t$ & $95 \% \mathrm{CI}$ \\
\hline \multicolumn{5}{|c|}{ High pain interference vs. low pain interference profile } \\
\hline Mental Health QOL & $-16.51 *$ & $-22.73,-10.28$ & -6.04 & $-15.89,3.81$ \\
\hline Depression & $6.97 *$ & $2.01,11.94$ & 1.95 & $-4.48,8.38$ \\
\hline Opioid use & -.70 & $-1.98, .58$ & -1.22 & $-2.74, .30$ \\
\hline Average pain interference & & & $3.07 *$ & $1.93,4.22$ \\
\hline Average pain intensity & & & $1.55^{*}$ & $.58,2.52$ \\
\hline \multicolumn{5}{|c|}{ High pain intensity profile vs. low pain intensity profile } \\
\hline Mental Health QOL & $-11.93 *$ & $-17.81,-6.05$ & -8.75 & $-15.74,-1.76$ \\
\hline Depression & 5.30 & $1.22,9.38$ & 2.72 & $-2.23,7.68$ \\
\hline Opioid use & -.68 & $-1.84, .47$ & -.71 & $-1.88, .47$ \\
\hline Average pain interference & & & $2.23 *$ & $1.29,3.17$ \\
\hline Average pain intensity & & & $2.41 *$ & $1.49,3.33$ \\
\hline
\end{tabular}

Note. *Significant based on corrected $p$-value for multiple comparisons (pain interference model: $p=.007$; pain intensity model: $p=.009$ ). Paired-sample $t-$ test. $95 \%$ confidence interval; lower bound, upper bound. 


\section{Figures}

Figure 1. Flow chart of the Prescription Opioid Addiction Treatment Study (POATS) clinical trial assessment timepoints, and timepoints (in bold text) used for the current study.

\section{Phase 1}

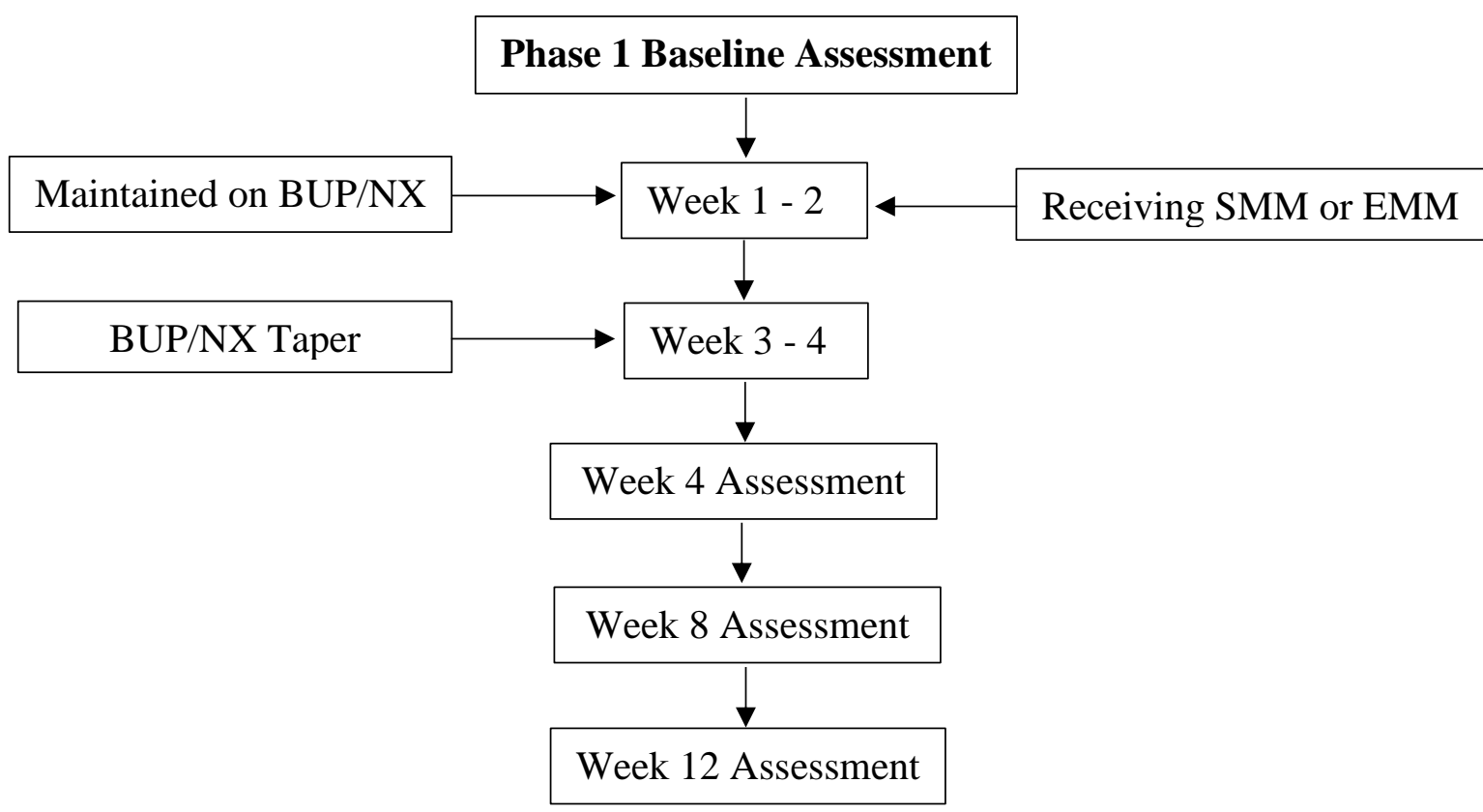

Phase 2

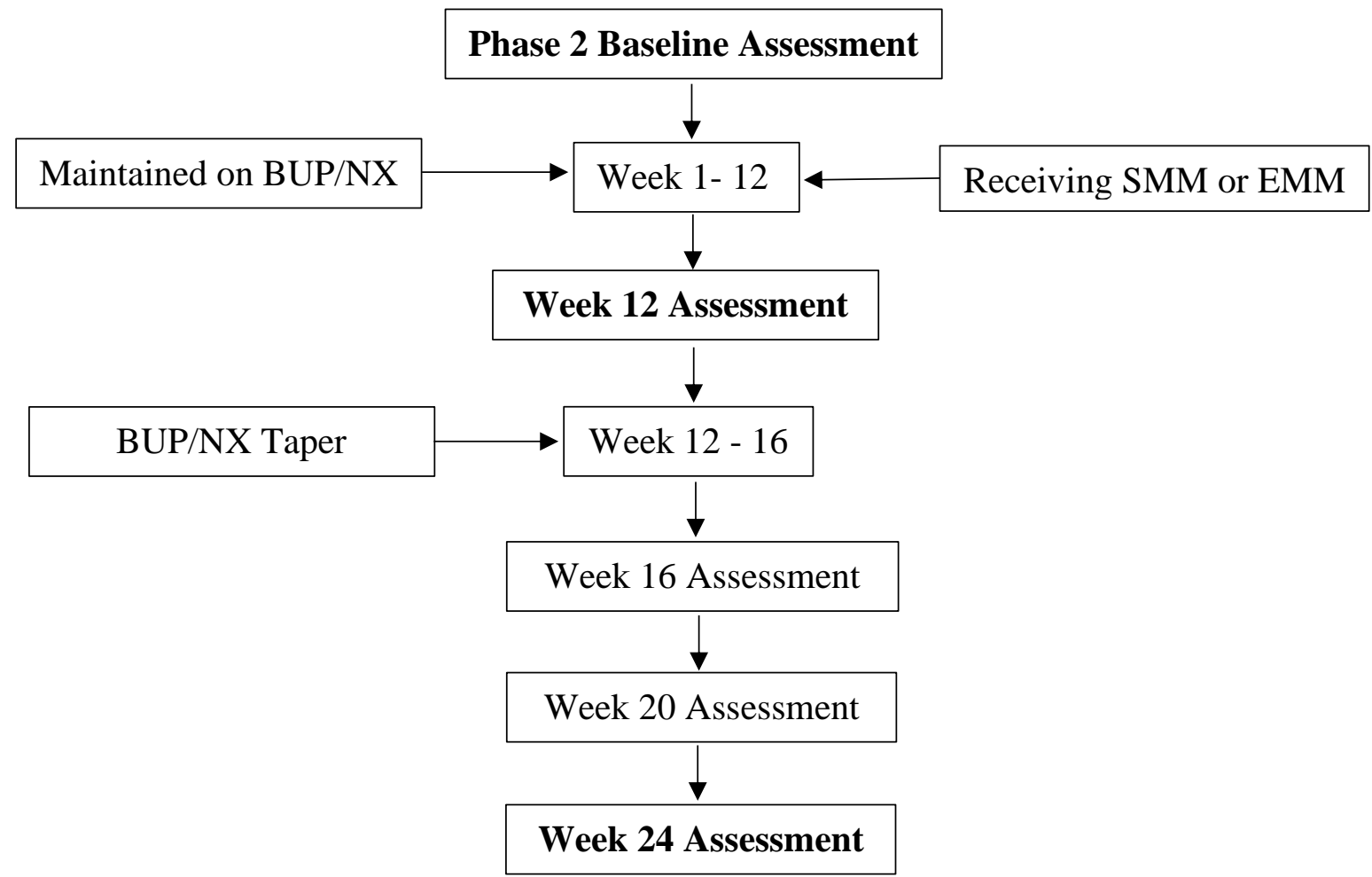


Figure 2. Mean indicator responses for the pain interference profiles at Phase 2 baseline.

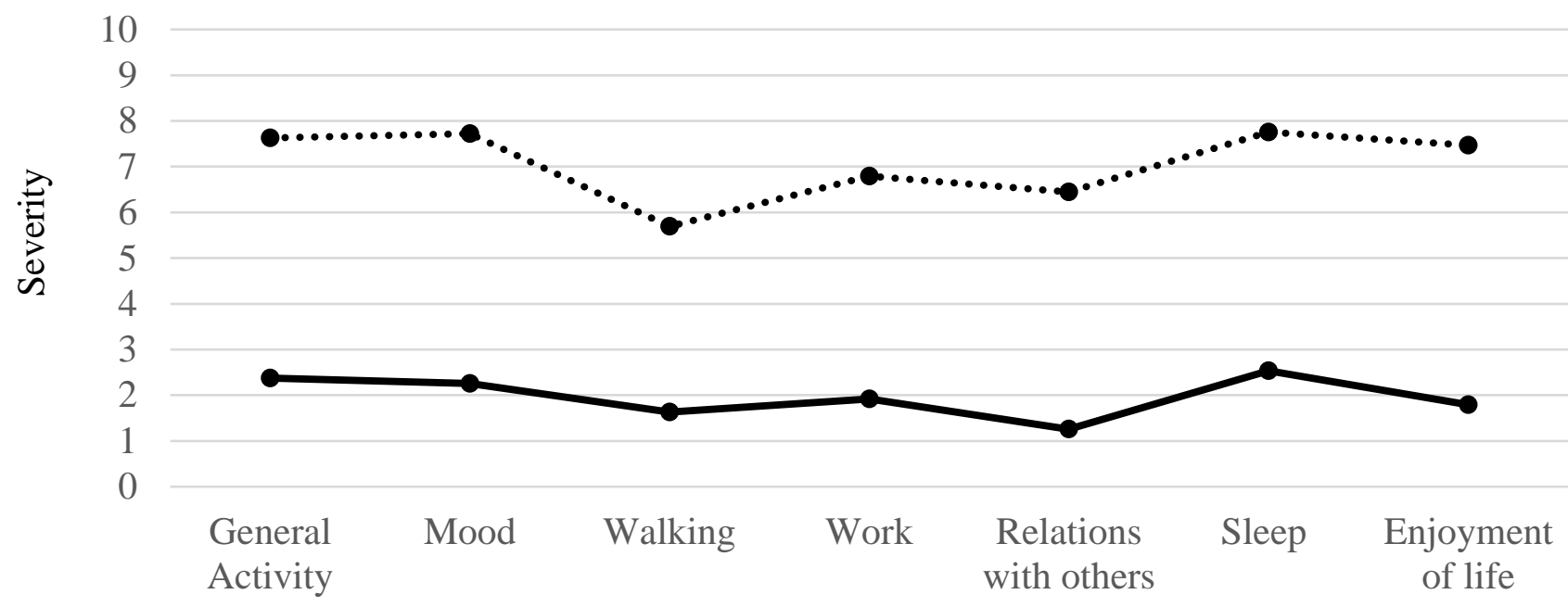

$\longrightarrow$ Low interference $(\mathrm{N}=118 ; 61 \%) \cdots \bullet$ High interference $(\mathrm{N}=76 ; 39 \%)$

Figure 3. Mean indicator responses for the pain intensity profiles at Phase 2 baseline.

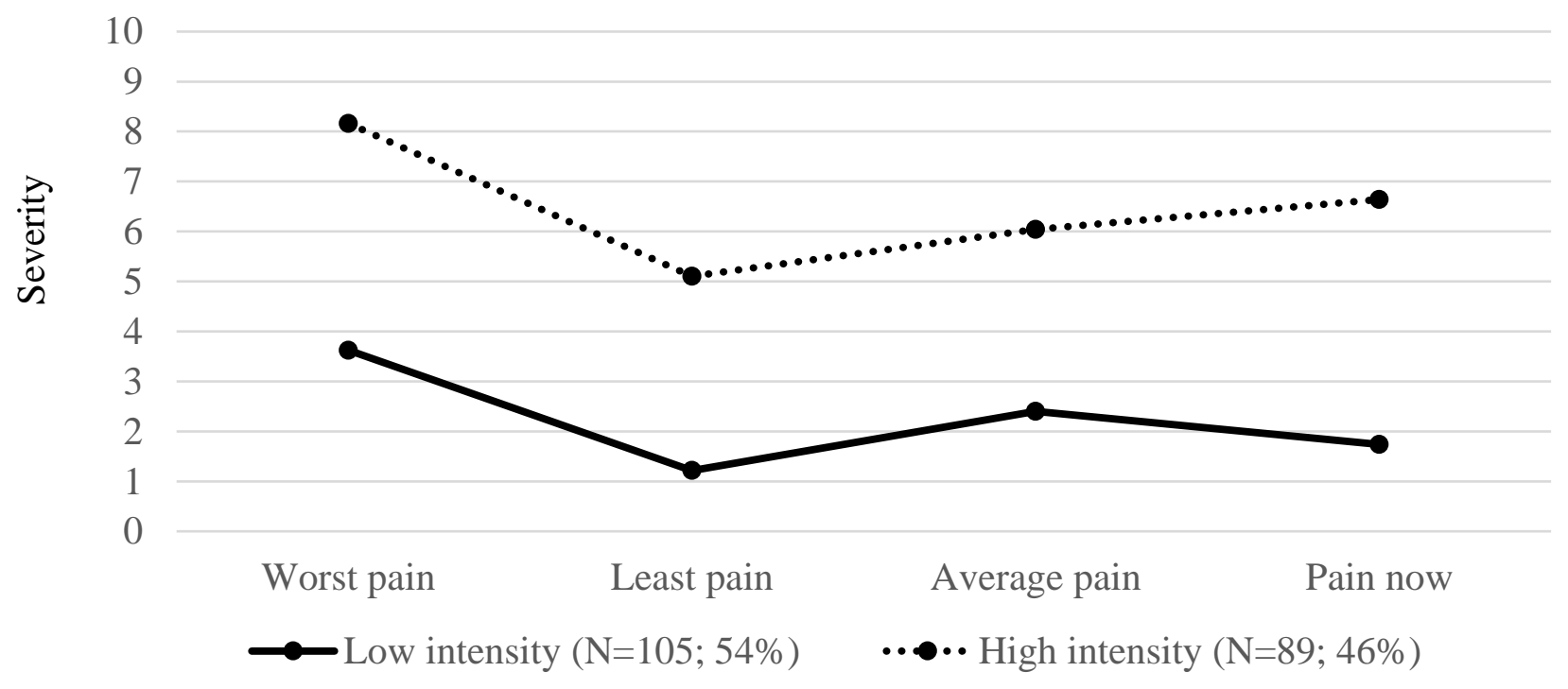

